Journal of Animal and Veterinary Advances 11 (16): 2964-2968, 2012

ISSN: $1680-5593$

(C) Medwell Journals, 2012

\title{
Effects of Different Fatty Source on Fatty Liver Performance and Composition of Fatty Liver in Landes Goose
}

\author{
${ }^{1}$ C. Zhang, ${ }^{2}$ C.J. Lian, ${ }^{2}$ Z.J. Yang, ${ }^{1}$ S.C. Sun, ${ }^{3}$ S.S. Zhou and ${ }^{1}$ S.L. Niu \\ ${ }^{1}$ Department of Veterinary, College of Animal Science, \\ Henan University of Science and Technology, 471000 Luoyang, Henan Province, P.R. China \\ ${ }^{2}$ Department of Animal Nutrition, College of Animal Science and Veterinary Medicine, \\ Jilin University, 130062 Changchun, Jilin Province, P.R. China \\ ${ }^{3}$ College of Biology, University of Camerino, St. Gentle III Camerino (MC), 62032, Italy
}

\begin{abstract}
The aim of this study was to investigate the effects of different dietary fatty source on fatty liver performance and liver nutritional components in the goose. The 450, 70 days old France Landaise geese were randomly divided into three groups after a pre-overfeeding week then the goose were given three carbohydrate-rich diet meals a day for 21 days of a carbohydrate-rich diet consisting of boiled and salted maize with $2 \%$ fat (goose fat, soybean oil and corn oil) and water added. On days 7 and 21 , the circulating levels of Alanine Transarninase (ALT), Glutamic-oxalacetic Transaminase (AST), Triglyeride (TG), Low-Density Lipoprotein (LDL), High Density Lipoprotein (HDL), Total Protein (TP), Cholesterol (CHOL) were determined. On day 21 , liver, abdominal adipose tissue and the left filet were removed. Water, crude protein, total lipids (ether extract) and fatty acid compositions were determined. The results showed that the lowest feed intake/liver weight was soybean oil group, highest was goose fat group but there was no significant statistical difference between them ( $>0.05)$. While there was a significant statistical difference between soybean oil group, corn oil group and goose fat group in liver/body and liver/dressed $(\mathrm{p}<0.05)$. The soybean oil group had the highest level of phosphatides (lecithin and cephalin). The contents of linoleic acid in soybean oil group were significantly higher than the goose fat group and corn oil group $(\mathrm{p}<0.05)$. It was indicated that the effects of soybean oil on the goose made more effective fatty liver production and more PUFA deposited in livers it was good for farmer income and people health.
\end{abstract}

Key words: Landaise goose, fatty source, fatty liver performance, fatty liver composition, people

\section{INTRODUCTION}

Under a reversible condition, fatty liver is large vacuoles of triglyceride fat accumulating in liver cells via the process of steatosis. In some palmipedes species (i.e., ducks and geese), increasing their energy and protein stores by eating more food for migration results in a large accumulation of lipids in the liver. This susceptibility to nutritional steatosis is particularly developed in some breeds (Mourot et al., 2000; Davail et al., 2003) and used for the production of fatty liver (foie gras) called the table of the Emperor (also known as inline bird meat). In response to overfeeding with a carbohydrate-rich corn-based diet, the goose liver weight may increase 10 fold in 2 weeks and account for up to $10 \%$ of body weight (Hermier et al., 1994). Whole grain corn is normally used for force-feeding geese during the fatty liver production period. Before feeding, the corn is cooked slightly in hot water until the kernels are just soft to a firm squeeze. Fat (often from birds which were previously used for fatty liver production) can be added up to $2 \%$ of the feed mixture for lubricating corns. Fat can increase the dietary energy level, further improve efficiency of feed utilization in pigs (Leskanich et al., 1997), same result was fund in broiler (Garrett and Young, 1975) also. But there is few research of different fatty source on fatty liver performance and composition of fatty liver in Landaise goose.

Lipid metabolism regulated by dietary Polyunsaturated Fatty Acids (PUFAs) has been largely investigated in mammals, including human (Jump et al., 1999) as known (for their recognized health effects), the aim of most studies was not to improve poultry health but to increase the proportion of PUFAs in meat or eggs for human consumption (Leskanich and Noble, 1997). And the fatty acid composition of body fat in birds were result in part of their dietary preferences of fatty source. Some

Corresponding Author: Shu Ling Niu, College of Animal Science and Veterinary, Jilin University, 130062 ChangChun, People's Republic of China 
studies showed that birds ate foods with more LongChain Unsaturated Fatty Acids (LCUFA) during migration (Heitmeyer and Fredrickson, 1990; Bairlein and Gwinner, 1994; Zurovchak et al., 1999) but there is no reseach on the effect of PUFAs on components of fatty acids in goose fatty liver. This project was focusing on the effect of different dietary fatty source on fatty liver performance and liver nutritional components in the goose.

\section{MATERIALS AND METHODS}

Animals and diets: A total of 450 France Landaise geese with 70 days old, hatched on the same day, body weight 4.5-5 kg were fed under natural light and temperature at the JLIN DELAI Goose Industry Co., Ltd. There was a 7 days pre-overfeeding period and a 21 days special diet period. During the pre-overfeeding week, they were given a basic diet (12.1 $\mathrm{MJ} \mathrm{kg}^{-1}, 194.6 \mathrm{~g}$ protein $\mathrm{kg}^{-1}$ ) then those birds were randomly divided into three groups each with three replicates, all groups of animals were given three carbohydrate-rich diet meals a day consisting of boiled and salted maize with $2 \%$ fat (goose fat $14.56 \mathrm{MJ} \mathrm{kg}^{-1}$, soybean oil $14.63 \mathrm{MJ} \mathrm{kg}^{-1}$, corn oil $14.63 \mathrm{MJ} \mathrm{kg}^{-1}$ ) for 21 days and water free. During the overfeeding period, every two birds was housed in an individual cage. At the end of overfeeding period and after one night fasting, the birds were sacrificed in a slaughter house by exsanguination under stunning after being weighted. Liver, abdominal adipose tissue and the left filet were removed.

Test index and methods: On day 6,20 of overfeeding, twelve geese of each group were deprived of food overnight for $12 \mathrm{~h}$ and provided with water. On the following morning (8:00 am to 8:30 am), blood was collected via puncture of the occipital venous sinus. Blood samples were divided into two portions. One portion was prepared for serum which was inversed and incubated at $37^{\circ} \mathrm{C}$ for $30-60 \mathrm{~min}$, incubated at $4^{\circ} \mathrm{C}$ overnight to let the clot contract. The serum was separated from the clot into a new centrifuge tube and centrifuged at $1,300 \times \mathrm{g}$ for $15 \mathrm{~min}$ to remove other materials. Another portion was prepared for plasma: blood samples were collected into centrifuge tubes containing EDTA-aprotinin (12.5 uL mL $\mathrm{mL}^{-1}$ of blood) and then centrifuged at $1,300 \times \mathrm{g}$ for $10 \mathrm{~min}$ at $4^{\circ} \mathrm{C}$. Plasma and serum were stored at $-70^{\circ} \mathrm{C}$.

On day 21 of overfeeding, 450 birds were deprived of feed overnight for $12 \mathrm{~h}$ and provided with water. All birds were weighted then immediately taken blood and sacrificed in a slaughter house by exsanguination while under electronarcosis. Then, the carcass weight and eviscerate percentage were measured. After one night at $4^{\circ} \mathrm{C}$ they were partly dissected: the liver, the abdominal adipose tissue and the left fillet were removed and weighed. Food intake was recorded daily during whole procession. Food intake/liver weight was calculated.

The measurements of Alanine Transarninase (ALT), Glutamic-Oxalacetic Transaminase (AST) Triglyeride (TG), Low-Density Lipoprotein (LDL), High Density Lipoprotein (HDL), Total Protein (TP), Cholesterol (CHOL) were determined by using an automatic multifunctionbiochemic alanalyzer (Hitachi Ltd., Japan) in department of Clinical Laboratory of Jilin hospital. Water, crude protein, total lipids (ether extract) and fatty acid compositions were determined in liver as earlier described in companion study (Zhou et al., 2009).

Statistical analysis: Statistical data were analyzed by SPSS 13.0 Software; all data were presented as mean \pm SE. The significance test was analyzed by multiple comparisons. Differences were considered highly significant at $\mathrm{p}<0.01$ and significant at $\mathrm{p}<0.05$.

\section{RESULTS}

Body and liver composition: After 21 days of over feeding, all groups Landaise geese had heavier liver weight than before over feeding (Table 1) as a consequence of their higher feed intake. Liver weight was $758.43 \pm 33.05,815.55 \pm 42.26$ and $801.75 \pm 49.92 \mathrm{~g}$ in goose fat group, soybean oil group and corn oil group. And there was a 7.53 and $5.72 \%$ higher liver weight in soybean oil group and corn oil group than goose fat group there were significant statistical differences $(\mathrm{p}<0.05)$. Likewise there were significant statistical differences between soybean oil group, corn oil group and goose fat group $(\mathrm{p}<0.05)$. The lowest feed intake/liver weight was soybean oil group, highest is goose fat group but there was no significant statistical difference $(\mathrm{p}>0.05)$.

The different fatty source had no significant effect on liver composition $(\mathrm{p}>0.05)$. Nevertheless, the soybean oil group had the highest levels of phosphatides (lecithin and cephalin) (Table 2). The different fatty source had no significant difference in most fatty acids of fatty liver after

Table 1: The liver production performance of Landes goose

\begin{tabular}{lcccc}
\hline Groups & $\begin{array}{c}\text { Liver weight } \\
(\mathrm{g})\end{array}$ & $\begin{array}{c}\text { Liver/body } \\
(\%)\end{array}$ & $\begin{array}{c}\text { Liver/dressed } \\
(\%)\end{array}$ & $\begin{array}{c}\text { Feed intake/ } \\
\text { liver weight }\end{array}$ \\
\hline Goose fat & $758.43 \pm 33.05^{\mathrm{a}}$ & $10.88 \pm 0.56^{\mathrm{a}}$ & $12.49 \pm 0.62^{\mathrm{a}}$ & $22.59 \pm 0.88$ \\
Soybean oil & $815.55 \pm 42.26^{\mathrm{b}}$ & $13.04 \pm 1.14^{\mathrm{b}}$ & $14.76 \pm 1.23^{\mathrm{b}}$ & $20.92 \pm 1.44$ \\
Corn oil & $801.75 \pm 49.92^{\mathrm{b}}$ & $12.65 \pm 0.79^{\mathrm{b}}$ & $14.25 \pm 1.28^{\mathrm{b}}$ & $22.27 \pm 1.73$ \\
\hline
\end{tabular}

Table 2: The composition of fatty liver of Landes geese

Water Crude Ether Lecithin Cephalin $\begin{array}{llllll}\text { Groups } & (\%) & \text { protein }(\%) & \text { extract }(\%) & (\%) & (\%)\end{array}$ \begin{tabular}{llllll}
\hline Goose fat & $45.20 \pm 2.13$ & $7.34 \pm 1.11$ & $38.45 \pm 5.59$ & $8.57 \pm 1.90$ & $0.72 \pm 0.39$
\end{tabular} $\begin{array}{lllllll}\text { Soybean oil } & 46.06 \pm 5.07 & 9.20 \pm 1.33 & 38.27 \pm 4.66 & 10.22 \pm 1.95 & 1.06 \pm 0.49\end{array}$ \begin{tabular}{llllll} 
Corn oil & $48.49 \pm 2.09$ & $7.73 \pm 1.66$ & $35.49 \pm 1.45$ & $8.67 \pm 0.98$ & $1.00 \pm 0.34$ \\
\hline
\end{tabular} Different lowercase superscripts in the same column of the same stage indicate significant differences $(p<0.05$ ) 
overfeeding except linoleic acid (Table 3 ). The contents of linoleic acid in soybean oil group were significantly higher than the goose fat group and corn oil group $(\mathrm{p}<0.05)$.

Fat storage index of Landes geese: After 21 days of over feeding, abdominal fatwas $316.66 \pm 26.19,218.33 \pm 21.66$ and $266.66 \pm 41.06 \mathrm{~g}$ in goose fat group, soybean oil group and corn oil group, respectively (Table 4). And there is a significantly difference between the goose fat group and the soybean oil group in abdominal fat. Similarly, the percentage of abdominal fat in soybean oil group was significantly lower thanfat group. Thickness of subcutaneous fat have no significantly difference among the three groups $(\mathrm{p}>0.05)$ but the soybean oil group had the lowest value.

Serum biochemical parameters of Landes geese: Blood was collected on the day before overfeeding as well as 7 and 21 days after overfeeding, serum biochemical parameters were quantified (Table 5). The result showed

Table 3: The main fatty acids of Landes geese liver

\begin{tabular}{lccc}
\hline Fatty acid & Goose fat group & Soybean oil group & Corn oil group \\
\hline Palmitic acid & $26.51 \pm 3.53$ & $24.01 \pm 1.38$ & $29.21 \pm 2.37$ \\
Palmitoleic acid & $2.26 \pm 0.62$ & $3.38 \pm 0.16$ & $3.11 \pm 0.90$ \\
Stearic acid & $14.37 \pm 0.85$ & $12.00 \pm 1.13$ & $13.17 \pm 0.79$ \\
Oleic acid & $54.94 \pm 2.49$ & $57.95 \pm 2.13$ & $52.55 \pm 1.88$ \\
Linoleic acid & $0.89 \pm 0.20^{\mathrm{a}}$ & $1.44 \pm 0.24^{\mathrm{b}}$ & $0.88 \pm 0.05^{\mathrm{a}}$ \\
Linolenic acid & $0.40 \pm 0.06$ & $0.49 \pm 0.05$ & $0.43 \pm 0.03$ \\
\hline
\end{tabular}

Table 4: The fat storage index of Landes geese

\begin{tabular}{|c|c|c|c|}
\hline \multirow[b]{2}{*}{ Fat storage index } & \multicolumn{3}{|l|}{ Groups } \\
\hline & Goose fat & Soybean oil & Corn oil \\
\hline Abdominal fat (g) & $316.66 \pm 26.19^{b}$ & $218.33 \pm 21.66^{\mathrm{a}}$ & $266.66 \pm 41.06^{a, b}$ \\
\hline $\begin{array}{l}\text { The percentage of } \\
\text { abdominal fat }(\%)\end{array}$ & $7.49 \pm 0.250^{b}$ & $5.58 \pm 0.650^{\mathrm{a}}$ & $7.44 \pm 1.430^{\mathrm{a}, \mathrm{b}}$ \\
\hline $\begin{array}{l}\text { Thickness of } \\
\text { subcutaneous fat }(\mathrm{cm})\end{array}$ & $1.30 \pm 0.150$ & $1.24 \pm 0.150$ & $1.35 \pm 0.310$ \\
\hline
\end{tabular}

that different fatty source had no significant effect on GLU, LDL, TP during overfeeding. But ALT in soybean oil group was significantly lower than other groups $(\mathrm{p}<0.05)$, the concentration of TG, HDL, CHOL in soybean oil group was significantly higher than other groups $(\mathrm{p}<0.05)$.

\section{DISCUSSION}

There are 3 nutrients (fat, protein and carbohydrates), fat plays an important role in animals, provides energy and aiding in the absorption of calcium and fat-soluble Vitamins ( $A, D, E$ and $K$ ). Fat is found in animal protein foods such as meat and egg yolks. Other important sources of fat are grains, nuts and seeds. In overfeeding period it made overfeeding easy because goose esophagus was lubricated by additional oil. Furthermore, additional oil also improved the utilization rate of food, made more fat accumulating in liver cells via the process of steatosis. In this experiment, all groups Landes geese had heavier liver weight than before over feeding (after 21 days of overfeeding) same as earlier reported (Hermier et al.,1994).

Landes goose is world wide famous for fatty liver production. How to make liver production more effectually becomes a topic. In this experiment, adding vegetable oil made more liver production than goose oil, especially soybean oil and there is less abdominal fat. It may be the reason why there is more PUFA in the vegetable oil. The effect of adding different fat on fat deposition in avian have a different result. In one the main effect of higher dietary PUFA being a reduction in abdominal fat in broiler chickens feeded isocaloric diets supplemented with different combinations of tallow and vegetable oil (Pinchasov and Nir, 1992). Sanz et al. (2000) found that

Table 5: The serum biochemical parameters of Landes geese

\begin{tabular}{|c|c|c|c|c|}
\hline Parameters & Period (weeks) & Goose fat group & Soybean oil group & Corn oil group \\
\hline \multirow[t]{2}{*}{$\mathrm{TG}\left(\mathrm{mmol} \mathrm{L}^{-1}\right)$} & Overfeeding 1 & $4.21 \pm 0.380$ & $4.74 \pm 0.790$ & $3.78 \pm 1.010$ \\
\hline & Overfeeding 3 & $5.59 \pm 0.300^{\mathrm{a}}$ & $9.22 \pm 3.360^{b}$ & $4.03 \pm 0.920^{\mathrm{a}}$ \\
\hline \multirow[t]{2}{*}{$\mathrm{HDL}\left(\mathrm{mmol} \mathrm{L}^{-1}\right)$} & Overfeeding 1 & $2.79 \pm 0.090$ & $2.47 \pm 0.260$ & $2.39 \pm 0.110$ \\
\hline & Overfeeding 3 & $4.84 \pm 0.490^{\mathrm{a}}$ & $6.12 \pm 0.280^{b}$ & $4.93 \pm 0.870^{\mathrm{a}}$ \\
\hline \multirow[t]{2}{*}{$\mathrm{LDL}\left(\mathrm{mmol} \mathrm{L}^{-1}\right)$} & Overfeeding 1 & $0.16 \pm 0.060$ & $0.30 \pm 0.100$ & $0.10 \pm 0.000$ \\
\hline & Overfeeding 3 & $2.00 \pm 0.150$ & $3.30 \pm 1.110$ & $3.03 \pm 0.590$ \\
\hline \multirow[t]{2}{*}{$\mathrm{GLU}\left(\mathrm{mmol} \mathrm{L}^{-1}\right)$} & Overfeeding 1 & $14.74 \pm 1.100$ & $14.64 \pm 0.580$ & $12.69 \pm 1.100$ \\
\hline & Overfeeding 3 & $14.53 \pm 0.440$ & $16.18 \pm 0.410$ & $15.92 \pm 0.550$ \\
\hline \multirow[t]{2}{*}{$\mathrm{CHOL}\left(\mathrm{mmol} \mathrm{L}^{-1}\right)$} & Overfeeding 1 & $4.82 \pm 0.240$ & $4.79 \pm 0.230$ & $4.41 \pm 0.260$ \\
\hline & Overfeeding 3 & $9.36 \pm 0.790^{\mathrm{a}}$ & $13.04 \pm 3.160^{b}$ & $9.79 \pm 1.450^{\mathrm{a}}$ \\
\hline \multirow[t]{2}{*}{$\operatorname{ALT}\left(\mathrm{u} \mathrm{L}^{-1}\right)$} & Overfeeding 1 & $22.00 \pm 4.930$ & $22.66 \pm 0.660$ & $25.33 \pm 6.980$ \\
\hline & Overfeeding 3 & $102.33 \pm 15.07^{\mathrm{b}}$ & $75.66 \pm 9.930^{\mathrm{a}}$ & $87.33 \pm 4.660^{\mathrm{a}}$ \\
\hline \multirow[t]{2}{*}{$\operatorname{AST}\left(\mathrm{u} \mathrm{L}^{-1}\right)$} & Overfeeding 1 & $21.66 \pm 2.600$ & $27.33 \pm 4.910$ & $30.66 \pm 5.660$ \\
\hline & Overfeeding 3 & $294.33 \pm 99.88$ & $424.33 \pm 65.56$ & $332.00 \pm 79.88$ \\
\hline \multirow[t]{2}{*}{$\mathrm{TP}\left(\mathrm{g} \mathrm{L}^{-1}\right)$} & Overfeeding 1 & $47.33 \pm 1.870^{\mathrm{a}}$ & $58.86 \pm 0.910^{c}$ & $49.96 \pm 5.870^{b}$ \\
\hline & Overfeeding 3 & $45.00 \pm 2.850$ & $48.63 \pm 1.010$ & $47.13 \pm 3.050$ \\
\hline
\end{tabular}

Different lowercase superscripts in the same column of the same stage indicate significant differences $(p<0.05)$ 
use of an unsaturated fat source during the first stages of growth and the substitution of a saturated fat for a few days before slaughter may offer the advantage of lower abdominal fat deposition and an acceptable fat fluidity compared with the use of a saturated fat source during the whole growing and finishing period (Sanz et al., 2000). Some similar results were also be found in other researchs (Crespo and Esteve-Garcia, 2001; Vila and Esteve-Garcia, 1996). Phetteplace and Watkins (1992) has a different results that there was no significant difference of fatty deposition in chicken broiler with colza oil, colza oil or fish oils.

It was proved that UFA can decrease the levels of TG, HLDL, LDL and TC by UFA, especially n- 3 and n- 6 fatty series (Hargis et al., 1991; Daggy et al., 1987; Phetteplace and Watkins, 1992; Mensink and Katan, 1990 , 1992). In the experiment researchers received a similar results.

The mechanism of hepatic steatosis involves cellular hypertrophy and hyperplasia (Leclercq et al., 1968). The weight of fatty liver depends on not noly geese breeds but also on the ability of cellular membranes synthesis which lipid moiety consists of free cholesterol, especially, phospholipids (Salichon and Guy, 1997). The present study indicate that there were more phospholipids deposited in livers in soybean group than the other groups for there were more phospholipids in soybean oil. This may be a reason that soybean group have a weighter liver.

Human nutritionists recommend to increase the proportion of Polyunsaturated Fatty Acids (PUFAs) in dietary lipids, especially n-3 series (Fernandes and Venkatraman, 1993; Roche, 1999). In the human, PUFAs have been shown to decrease a number of risk factors of atherosclerosis and thrombosis such as plasma triglycerides, Very Low Density Lipoproteins (VLDL) (Harris, 1989), systolic blood pressure (Norris et al., 1986) and platelet function (Goodnight et al., 1981). Thus, the geeses meat and fatty liver rich with PUFAs might recognized as a factor of beneficial health effects.

\section{CONCLUSION}

The present study describes the effects of soybean oil on the geese, make a more effective fatty liver production and more PUFA deposited in livers it is better for farmer income and peopels health.

\section{REFERENCES}

Bairlein, F. and E. Gwinner, 1994. Nutritional mechanisms and temporal control of migratory energy accumulation in birds Annu. Rev. Nutr., 14: 187-215.
Crespo, N. and E. Esteve-Garcia, 2001. Dietary fatty acid profile modifies abdominal fat deposition in broiler chickens Poult. Sci., 80: 71-78.

Daggy, B., C. Arost and A. Bensadoun, 1987. Dietary fish oil decreases hepatic VLDL output in normal and hypercholesterolemic roosters Biochim. Biophys. Acta., 920: 293-300.

Davail, S., N. Rideau, G. Guy, J.M. Andre, D. Hermier and R. Hoo-Paris, 2003. Hormonal and metabolic responses to overfeeding in three genotypes of ducks Comp. Biochem. Physiol. A Mol. Integr. Physiol., 134: 707-715.

Fernandes, G. and J.T. Venkatraman, 1993. Role of omega3 fats in health and disease Nutr. Res., 13: S19-S45.

Garrett, R.L. and J. Young, 1975. Effect of Micelle Formation on the Absorption of Neutral Fat and Fatty Acids by the Chicken J. Nutr., 105: 827-833.

Goodnight, S.H., W.S. Harris and W.E. Connor, 1981. The effects of dietary w3 fatty acids on platelet composition and function in man: A prospective, controlled trial. Blood, 58: 880-885.

Hargis, P.S., M.E. van Elswyk and B.M. Hargis, 1991. Dietary modification of yolk lipid with menhaden oil. Poult. Sci., 70: 874-883.

Harris, W.S., 1989. Fish oils and plasma lipid and lipoprotein metabolism in humans: A critical review. J. Lipid Res., 30: 785-807.

Heitmeyer, M.E. and L.H. Fredrickson, 1990. Fatty acid composition of wintering female mallards in relation to nutrient use J. Wildl. Manage., 54: 54-61.

Hermier, D., D. Rousselot-Pailley, R. Peresson and N. Sellier, 1994. Influence of orotic acid and estrogen on hepatic lipid storage and secretion in the goose susceptible to liver steatosis Biochem. Biophys. Acta, 1211: 97-106.

Jump, D.B., A. Thelen, B. Ren and M. Mater, 1999. Multiple mechanisms for polyunsaturated regulation of hepatic gene transcription Prost. Leuk. Essent. Fatty Acids., 60: 345-349.

Leclercq, B., G. Durand, P. Delpech and J.C. Blum, 1968. Note pre liminaire sur levolution des constituants biochimiques du foie au cours du gavage de loie Ann. Biol. Anim. Bioch. Biophys., 8: 549-556.

Leskanich, C.O. and R.C. Noble, 1997. Manipulation of the n-3 polyunsaturated fatty acid of avian eggs and meat. Worlds Poult. Sci. J., 53: 155-183.

Leskanich, C.O., K.R. Matthews, C.C. Warkup, R.C. Noble and M. Hazzledine, 1997. The effect of dietary oil containing (n-3) fatty acids on the fatty acid, physicochemical and organoleptic characteristics of pig meat and fat J. Anim. Sci., 75: 673-683. 
Mensink, R.P. and M.B. Katan, 1990. Effect of dietary trans fatty acids on high-density and low-density lipoprotein cholesterol levels in healthy subjects N. Engl. J. Med., 323: 439-445.

Mensink, R.P. and M.B. Katan, 1992. Effect of dietary fatty acids on serum lipids and lipoproteins. A metaanalysis of 27 trials. Arteriosclerosis Thrombosis Vasc. Biol., 12: 911-919.

Mourot, J., G. Guy, S. Lagarrigue, P. Peiniau and D. Hermier, 2000. Role of hepatic lipogenesis in the susceptibility to fatty liver in the goose (Anser anser). Comp. Biochem. Physiol. Part B: Biochem. Mol. Biol., 126: 81-87.

Norris, P.J., C.J. Jones and M.J. Weston, 1986. Effect of dietary supplementation with fish oil on systolic blood pressure in mild essential hypertension $\mathrm{Br}$. Med. J., 293: 104-105.

Phetteplace, H.W. and B.A. Watkins, 1992. Influence of dietary $n-6$ and $n-3$ polyunsaturates on lipids in chickens divergently selected for body weight. Poul Sci., 71: 1513-1519.

Pinchasov, Y. and I. Nir, 1992. Effect of dietary polyunsaturated fatty acid concentration on performance, fat deposition and carcass fatty acid composition in broiler chickens. Poult. Sci., 71: 1504-1512.
Roche, H.M., 1999. Unsaturated fatty acids Proc. Nutr. Soc., 58q1: 397-401.

Salichon, M.R., G. Guy, 1997. Hepatic lipid metabolism in relation to fatty liver production in the goose Euro. Symp. Waterfowl, Nantes.

Sanz, M., C.J. Lopez-Bote, A. Flores and J.M. Carmona, 2000. Effect of the inclusion time of dietary saturated and unsaturated fats before slaughter on the accumulation and composition of abdominal fat in female broiler chickens. Poult. Sci., 79: 1320-1325.

Vila, B. and E. Esteve-Garcia, 1996. Studies on acid oils and fatty acids for chickens. I. Influence of age, rate of inclusion and degree of saturation on fat digestibility and metabolisable energy of acid oils. Br. Poult. Sci., 37: 105-117.

Zhou, S.S., S.1. Niu and Z. Jing, 2009. Effect of differential fat sources on liver production and blood biochemical indices of Landes geese. China Anim. Husbandry Veterinary Med., 36: 27-29.

Zurovchak, J.G., E.W. Stiles and A.R. Place, 1999. Effect of dietary lipid level on lipid passage rate and lipid absorption efficiency in American Robins (Turdus migratorius) J. Exp. Zool., 283: 408-417. 